\title{
ADVANCEMENT OF A WALL CLIMBING ROBOT FOR VARIOUS APPLICATIONS
}

\author{
Pawar Mansi Shailendrasingh ${ }^{1}$, Lad Pranav Pratap ${ }^{2}$ \\ ${ }^{I}$ Student, Electronics and Instrumentation, VIT University Vellore, Tamil Nadu, India \\ ${ }^{2}$ Student, Production and Industrial Engineering, VIT University Vellore, Tamil Nadu, India
}

\begin{abstract}
In this project we introduced the integration of ultrasonic and total foundation for walls and bridges geometry surveying system and a motion planning implementation. With the quick development of construction industry the construction quality is also extensively paid attention. This project concentrates mainly on the strength detection of the wall as well as the cracks in the wall. The removal of air from the suction cup is utilized to make the robot stick to the wall. It is similar to suction cup where vacuum pressure of a particular amount of area moderately gets exhausted by an air pump. The robot can automate tasks in a cost effective manner which are done manually with an extra degreed of human safety. The robots are required to have high maneuverability and expeditious attachment and detachment. The entire platform can find applications in angle bending and vibration alert for high rise buildings, sensing applications like weather monitoring station and moisture in the walls as well as bridges etc. It also has the ability of crossing obstacles, motion control function, effective/surveillance, wireless communication relevant to the effective situation and the ability to distinguish the obstacles avoider situation. Even though the design of the robot is uncomplicated, it will be able to climb porous surfaces. A wireless communication link is used for high performance robotic system. The results demonstrate the low maintenance cost system and also states that the production cost is comparatively very less than the actual production cost of the method used presently. The principle and design of the climbing robot is pneumatic based.
\end{abstract}

Keywords: Robot, Climber, Suction Cups, DC Motor, Wireless Control

\section{INTRODUCTION}

The degree of surface crack in a wall becomes an important standard to hold the quality of the wall. It also depends on the moisture content in line to the surrounding temperature. Therefore detection of surface cracks in building walls has been a fevered research field of construction.

In this paper, we propose a wall-climbing robot based on adhesive mechanism. It has various other features like in vibration alert if heavy loaded vehicles are passing over a bridge, angle bending in the bridge foundations, moisture content in the walls and various sensing applications like motion control, obstacle detector and autonomous work. The robot takes on risky tasks in unsafe environments too. The Wall Climbing Robot has been constructed based on limb function.

\subsection{Visual Literature}

Engineers face the call to have a look for damage in the walls and bridges that need to be repaired or replaced. A normal engineer goes through the documents and checks the age of the wall. Nowadays visual inspection is carried out for this purpose. Even if some cracks don't suggest being severe depending on their position while the others may cause unpredictable accidents. Cracks mostly form, propagate and sicken in the form of the calefaction, thermal stress, and heavy loads, repeatedly pounding and vibration on the part. Even if the cracks are very macroscopical, they may not stick together in the same way. Pillar cracks developed and shifted from foundation and not bearing and transmitting load. That means if there is larger load of vehicles than the bridges can handle then the area will suffer from more stress than it can take. Other flaws such as angle bending in walls, moisture, traffic interrupt, and porosity leaks need to be diagnosed for further replacement and repairing. With hard-to-find and high value cores and parts, the decision may hinge on the extent of the damage. Various other methods are used for detection of cracks in walls and pillars mainly dry penetration test, Liquid penetration test, pressure testing, ultrasonic and vacuum testing.

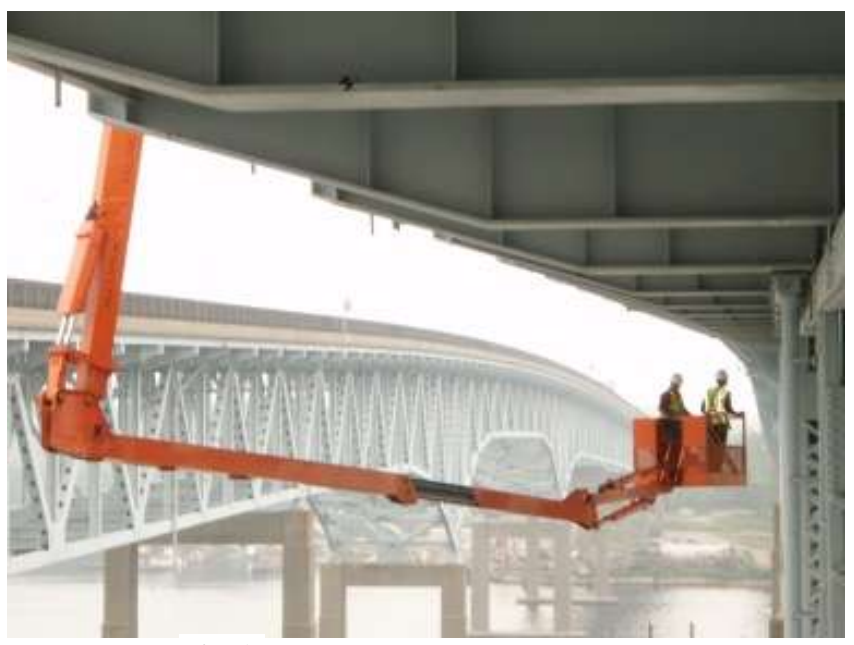

Fig 1- Site of manual bridge testing 


\subsection{Crack Detection}

Cracks are detected by ultrasonic testing. Ultrasonic testing is usually used for various industrial applications such as metal detection and finding glitches in walls and pillars of a building. It is a common non-destructive tool for investigating cracks in structures. Here the acoustic signal may vary up to $20 \mathrm{Mhz}$. The cracks will pass back on the detector in form of sound waves. On an LCD display the output will be displayed. This output can be transferred using Bluetooth module. Ultrasonic testing is one of the best methods because it can find minute cracks also because of its high penetrating power. Higher sensitivity results in detecting the smallest cracks possible.

\section{Method and Material}

There are various loco motions from which a wall climbing robot can be formed. Limb and Pneumatic system is used for the locomotion. In this suction adhesion robot the onboard pump is used that creates a pressure drop inside the suction cups that are pressed against the wall or ceiling. As the suction cups are pressured against the wall, the on board pump will start to inject the air in the vacuum cup out to the surrounding. After a while, the pressure inside the vacuum cup is lower than that outside the vacuum cup thus it is able to "stick" onto the wall. The mechanism of the robot can be represented as two limb/leg robot. When one leg is holding the wall, the other leg moves in upward direction. The movement of the other leg is caused due to the actuation of the motor above the holding leg. The moving leg holds to the wall after moving a particular distance and makes the movement of the other leg by the same process. This loco motion process continues.

The locomotion of the robot can be divided into adhesive mechanism and the driver system. Wall climbing robots perform stably only on smooth and flat surfaces. The Pneumatic system fails on porous surfaces. But here the robot comprises of large number of suction cups. So even if half of the suction cups fail, the robot holds on to the wall (refer Fig 4). This will also maintain the speed of the robot as it acquires the particular amount of pressure to stick on the wall. For control of suction we have used two solenoid valves, which switch the suction between two limbs/legs. The work of individual solenoid is to alternatively relay the generated vacuum.

The robot consists of aluminum steel alloy used for frame, motors, vacuum cups and pipes. The center of gravity of the robot is maintained very near to the limbs of the robot as conceivable, so that the total vacuum to be generated will be low as per the force required. The materials used are light weight to overcome the main aspect that is gravity. There are other aspects that affect the holding to the wall that are the forces, motion of the robot and design.

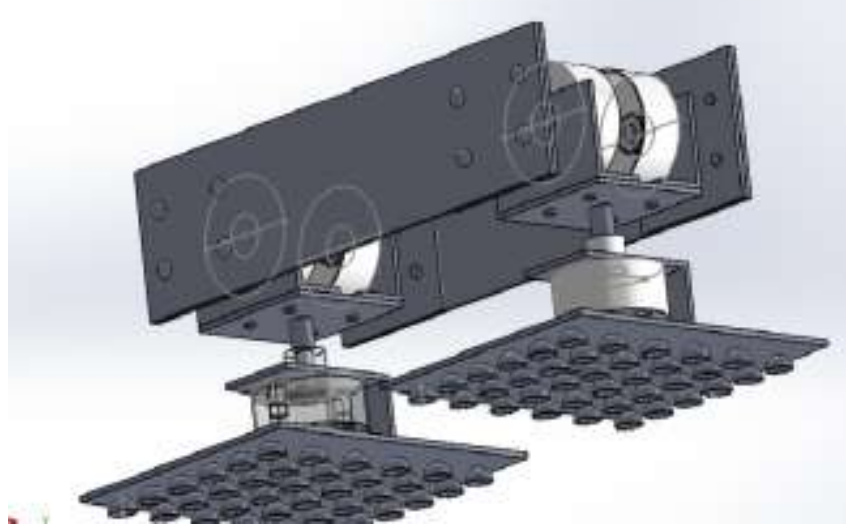

Fig -2(a): Solid works model of the Wall Climbing Robot

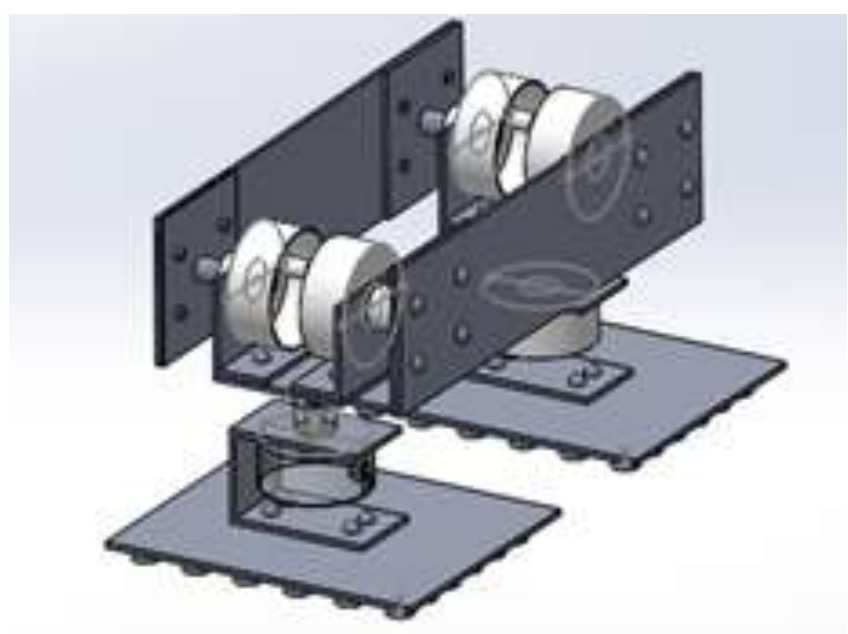

Fig -2(b): Top view of the Wall Climbing Robot

\subsection{Calculations and analysis:}

Suction cup:

Radius $(\mathrm{ra})=1 \mathrm{~cm}$

Total number of cups $=36$

Small Pipe:

Length $(\mathrm{L} 1)=4 \mathrm{~cm}$

Radius (rb) $=0.3 \mathrm{~cm}$

No. of small pipes $=36$

Suction cup volume $=2 / 3\left(\mathrm{Pi}^{*} \mathrm{ra}^{3}\right)$

$$
=2 / 3 * 3.14 * 1^{3}
$$

$$
=2.093 \mathrm{~cm}^{3}
$$

Small pipe volume $=\mathrm{Pi}^{*} \mathrm{rb}^{2} * \mathrm{~h}$

$$
\begin{aligned}
& =3.14 *(0.8)^{2} * 200 \\
& =401.92 \mathrm{~cm}^{3}
\end{aligned}
$$

Small suction cups in total $=36$

Total volume to be generated $=36 * 2.093$

$$
=75.348 \mathrm{~cm}^{3}
$$

Small pipes are joined to main pipe

Small pipes joining to each suction cup $=36$

Total volume to be generated in small pipes $=36 * 1.1304$ $=40.6944 \mathrm{~cm}^{3}$

Total volume in pump reservoir equals $=2.25 \mathrm{qt}$ (US liquid quart)

Suction should be generated $=$ Pump reservoir volume + suction cup volume + total pipe volume 
$=2129.294+40.6944+401.92+75.348$

$=2647.4924$

Specified LPM $=1601 \mathrm{pm}$

Capacity of suction $=(160 * 10 * 10 * 10) / 60$

$$
=2666.667 \mathrm{~m}^{3} / \mathrm{s}
$$

This is more than required in comparison with total suction to be generated.

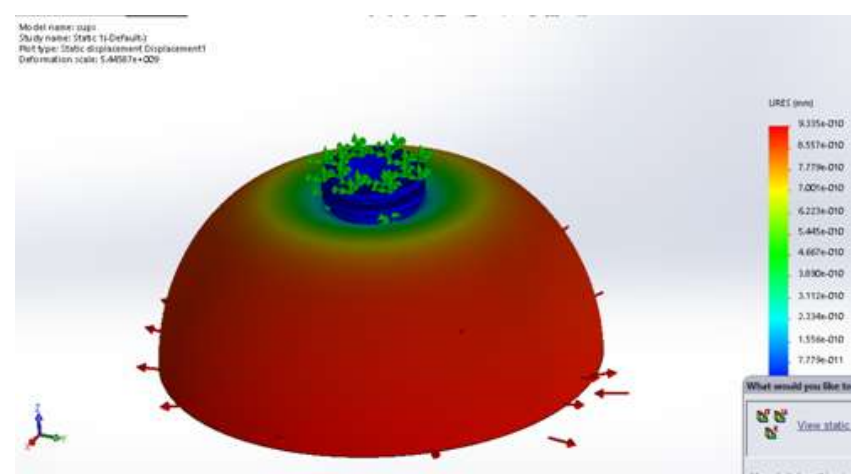

Fig -4: Displacement analysis of suction cup, MaterialSilicon; Red color indicates more displacement.

Table -1: Name of the Table

\begin{tabular}{|c|c|}
\hline Parameter & Feature \\
\hline Dimensions of robot & $\begin{array}{l}45 \mathrm{~cm} \times 45 \mathrm{~cm} \times 10 \mathrm{~cm} \\
\text { (excluding cables) }\end{array}$ \\
\hline Weight of robot & $2.4 \mathrm{kgs}$ \\
\hline Suction cups & Disc type, $1 \mathrm{~cm}$ radius \\
\hline Driver & $\begin{array}{l}\text { Nominal voltage:5 V } \\
\text { Maximum } \quad \text { current: } \\
1.1 \mathrm{~mA} \\
\text { No load speed: } 20 \mathrm{rpm}\end{array}$ \\
\hline Speed & $0.10 \mathrm{~m} / \mathrm{s}$ \\
\hline Payload & $3.5 \mathrm{~kg}$ \\
\hline Relays & 2 of $12 \mathrm{v}$ each \\
\hline Solenoid Valves & 2 of $24 \mathrm{v}$ each \\
\hline Control & $\begin{array}{l}\text { PWM for servo motors. } \\
\text { RF Transceivers range: } \\
100 \mathrm{~m} \\
\text { Semi-autonomous }\end{array}$ \\
\hline Vaccum pump & $\begin{array}{l}\text { Suction type: non } \\
\text { destructive suction }\end{array}$ \\
\hline Adhesion Mechanism & $\begin{array}{l}160 \mathrm{lpm}, 2880 \mathrm{rpm}, 0.5 \\
\mathrm{HP}, 230 \mathrm{~V}\end{array}$ \\
\hline
\end{tabular}

\section{CONCLUSIONS}

Although the robotics technologies showcase the Wall Climbing Robots for various cleaning applications but now it can check vibrations and stability in bridges also. This consecutively results in shortening the human accident rates. This will contribute to the population rate of humans. The applications of detection method for surface crack in walls and bridges are very extensive and have attracted more and more scholars. The design of the robot is very simplified, user-friendly, and cost effective and movement is faster in comparison to other climbing robots.

\section{REFERENCES}

[1]. A. T. Asbeck, S. Kim, A. McClung, A. Parness, "Climbing Walls with Microspines," IEEE International Conference on Robotics and Automation, Orlando, 2006.

[2]. Hirose, S., Nagakubo, A., and Toyama, R. (1991). Machine that can walk and climb on floors, walls and ceilings. Fifth International Conference on Advanced Robotics, 1991. 'Robots in Unstructured Environments', 91 ICAR, vol. 1, pp. 753-758, 19 Jun 1991-22 Jun 1991 Pisa , Italy.

[3]. Asbeck A T, Kim S, Cutkosky M R, Provancher W R, Lanzetta M (2006) Scaling hard vertical surfaces with compliant microspine array $[\mathrm{J}]$. International Journal of Robotics Research, 2006, 25(12): 1165-1179.

[4]. Li H K, Dai Z D, Shi A J (2008) Big house lizard in the vertical and horizontal surfaces on the trot walking and joint angle observation. Chinese Science Bulletin, 53(22): 26972703.

[5] Gupta S (2011) Sticky feet send insect-bot climbing up the walls. New Scientist, 209(2801): 24-24.

[6] A.T. Asbeck, S. Kim, A. McClung, A. Parness, "Climbing Walls with Microspines," IEEE International Conference on Robotics and Automation, Orlando, 2006.

[7] X. W. GUAN, H. ZHANG, A. H. JI, Z. D. DAI, "Development of claw inspired foot structure for wallclimbing robot," Mechanical \& Electrical Engineering Magazine, vol. 26, no. 2, pp. 1-4, 2009.

\section{BIOGRAPHIES}

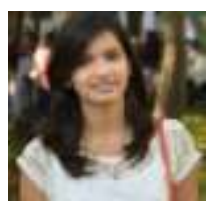

[1] Pawar Mansi Shailendrasingh

I am a Btech third year student studying Electronics and Instrumentation Engineering at Vellore Institute of Technology Vellore. I am a passionate engineering student having a strong predilection towards Robotics and Automation. I have laid more stress on projects and technical activities. Launched the Project Recognition Plans to give recognition to the members for the projects they do. Conducted various sessions and guided the juniors such as Manual Robotics, Robowars and sensor interfacing.

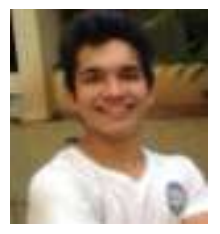

\section{[2] Lad Pranav Pratap}

I am a Btech third year student studying Production and Industrial Engineering at Vellore Institute of Technology Vellore. I am a passionate engineering student having a strong predilection towards Robotics and Manufacturing Automation. Conducted various sessions and guided the juniors such as Robotic arm and Solid works and other designing softwares. 